Supplementary information

\title{
Oil palm cultivation can be expanded while sparing biodiversity in India
}

In the format provided by the authors and unedited 


\section{Supplementary Information for:}

\section{"Oil palm cultivation can be expanded while sparing biodiversity in India"}

\section{Authors:}

Umesh Srinivasan $^{1,2 *}$, Nandini Velho ${ }^{3}$, Janice Ser Huay Lee ${ }^{2,4}$, Davide Danilo Chiarelli ${ }^{5}$, Kyle Frankel Davis ${ }^{6,7} \&$ David S. Wilcove $e^{2,7}$

\section{Affiliations:}

${ }^{1}$ Centre for Ecological Sciences, Indian Institute of Science, Bangalore 560012, INDIA

${ }^{2}$ Program in Science, Technology and Environmental Policy, Princeton School of Public and International Affairs, Princeton University, Princeton NJ 08544, USA (umesh.srinivasan@gmail.com).

${ }^{3}$ Srishti Manipal Institute of Art, Design and Technology, Bangalore 560106, INDIA.

${ }^{4}$ Asian School of the Environment, Earth Observatory Singapore, Nanyang Technological University, Singapore 639798, SINGAPORE.

${ }^{5}$ Department of Civil and Environment Engineering, Politecnico di Milano, Milan 20133, Italy.

${ }^{6}$ Department of Geography and Spatial Sciences, University of Delaware, Newark, DE 19716, USA.

${ }^{7}$ Department of Plant and Soil Sciences, University of Delaware, Newark, DE 19716, USA.

${ }^{8}$ Department of Ecology and Evolutionary Biology, Princeton University, Princeton NJ 08544, USA. 


\section{Supplementary Information 1}

\section{Calculating the water footprints of oil palm and rice}

\section{Data sources}

Crop water requirements (CWRs) were calculated based on data from the years 2000 to 2009 .

CWRs were split between 'blue' and 'green' CWRs - green water is supplied through rainfall and blue water through irrigation from surface and groundwater sources ${ }^{1}$. Data on precipitation were taken from the Indian Meteorological Department's $1.0^{\circ}$ x $1.0^{\circ}$ daily rainfall product ${ }^{2}$. Mean daily temperatures were taken from the University of East Anglia's Climate Research Unit CRU TS3.10 dataset $^{3}$. Wind speed and relative humidity data were derived from the National Oceanic and Atmospheric Administration's (NOAA) reanalysis product ${ }^{4}$. Soil information came from the Food and Agriculture Organization (FAO) of the United Nations Harmonized World Soil Database map ${ }^{5}$. Data for net radiation at the surface (which also accounts for soil heat flux density) were taken from the National Aeronautics and Space Administration's (NASA) Global Land Data Assimilation System Noah Land Surface Model L4 monthly $0.25^{\circ}$ x $0.25^{\circ}$ degree, version $2.0^{6}$. Crop coefficients, planting dates, growing stages, and climate regions came from [7].

\section{Estimating atmospheric demands on crops}

Following [7-9], reference evapotranspiration, $E T_{o}$, was calculated at monthly time steps at the district level using the FAO's Penmann Monteith Equation ${ }^{10}$ :

$$
E T_{0}=\frac{0.408 \Delta R_{n}-G+\gamma \frac{900}{T+273} u_{2} e_{5}-e_{a}}{\Delta+\gamma 1+0.34 u_{2}}
$$

where $R_{n}$ is the net radiation at the crop surface $\left(\mathrm{MJ} \mathrm{m}^{-2}\right.$ day $\left.^{-1}\right), G$ is the soil heat flux density (MJ m ${ }^{2}$ day $\left.^{-1}\right), T$ is the mean daily air temperature at 2 meters $\left({ }^{\circ} \mathrm{C}\right), u_{2}$ is the wind speed at 2 meters $\left(\mathrm{m} \mathrm{s}^{-1}\right)$, $e_{s}$ and $e_{a}$ are the saturation and deficit vapor pressures, respectively $(\mathrm{kPa}), \Delta$ is the slope vapor pressure curve $\left(\mathrm{kPa}^{\circ} \mathrm{C}^{-1}\right)$, and $\gamma$ is the psychrometric constant $\left(\mathrm{kPa}^{\circ} \mathrm{C}^{-1}\right)$. To determine crop-specific evapotranspiration $\left(E T_{c}\right), E T_{o}$ was then multiplied by a crop coefficient, $k_{c}$, which is dependent on 
the month, planting date of the crop, and growing stage ${ }^{11}$; Supplementary Table 2). Following [10], $\Delta, \gamma, e_{s}$, and $e_{a}$ were derived from the temperature and relative humidity data listed above.

\section{Solving the soil water balance}

We used the WATNEEDS model ${ }^{12}$ to solve the soil water balance for oil palm and rice to determine the volume of water $\left(\mathrm{mm} \mathrm{yr}^{-1}\right)$ required to prevent each of these crops from dropping below their respective levels of readily available water (i.e., the level of soil moisture below which a plant can no longer extract water from the soil). Information on soil texture ${ }^{5}$ was used to determine field capacity (i.e., the volume of arriving moisture that can be retained in the soil), wilting point, runoff, and deep percolation ${ }^{10}$. If precipitation was insufficient to meet the total CWR (i.e., $E T_{c}$ ), the model added water through irrigation to prevent the crop from dropping below its wilting point. In this way, we were able to determine a 'green' CWR (provided by precipitation) and a 'blue' CWR (provided through deficit irrigation). After running the model for each time step, we then took a summation of the monthly CWRs to determine total 'blue' and 'green' crop water requirements for a growing season. In the case of oil palm, this encompassed the whole year. While our calculated CWR values are based on current (2000-2009) climate conditions, recent work has shown that the choice of crop can have a far greater impact on an area's crop water demand than alterations in precipitation and temperature from climate change ${ }^{13}$. Thus, we do not expect substantial changes in the CWRs of either crop within the future scenarios considered here.

\section{References}

1. Falkenmark, M. \& Rockström, J. Balancing Water for Humans and Nature: The New Approach in Ecohydrology. (Routledge, 2004).

2. Rajeevan, M., Bhate, J., Kale, J. \& Lal, B. High resolution daily gridded rainfall data for the Indian region: analysis of break and active monsoon spells. Current Science 91, 296-306 (2006).

3. Harris, I. P. D. J., Jones, P. D., Osborn, T. J. \& Lister, D. H. Updated high-resolution grids of 
monthly climatic observations-the CRU TS3. 10 Dataset. International Journal of Climatology 34, 623-642 (2014).

4. Kalnay, E., Kanamitsu, M., Kistler, R., Collins, W., Deaven, D., Gandin, L., Iredell, M., Saha, S., White, G., Woollen, J. \& Zhu, Y. The NCEP/NCAR 40-year reanalysis project. Bulletin of the American Meteorological Society 77, 437-472 (1996).

5. Nachtergaele, F., van Velthuizen, H. \& Verelst, L. Harmonized World Soil Database Version 1.2. Food and Agriculture Organization of the United Nations (FAO). International Institute for Applied Systems Analysis (IIASA), ISRIC-World Soil Information, Institute of Soil ScienceChinese Academy of Sciences (ISSCAS), Joint Research Centre of the European Commission (JRC) (2012).

6. Beaudoing, H. \& Rodell, M. GLDAS Noah Land Surface Model L4 3 hourly $0.25 \times 0.25$ degree V2. 1 (Goddard Earth Sciences Data and Information Services Center: Greenbelt, MD, USA, 2016).

7. Mekonnen, M. M. \& Hoekstra, A. Y. The green, blue and grey water footprint of crops and derived crop products. Hydrology and Earth System Sciences 15, 1577 (2011).

8. Davis, K. F., Rulli, M. C., Seveso, A. \& D’Odorico, P. Increased food production and reduced water use through optimized crop distribution. Nature Geoscience 10, 919-924 (2017).

9. Davis, K. F., Chiarelli, D. D., Rulli, M. C., Chhatre, A., Richter, B., Singh, D. \& DeFries, R. Alternative cereals can improve water use and nutrient supply in India. Science Advances $\mathbf{4}$ eaao1108 (2018).

10. Allen, R. G., Pereira, L. S., Raes, D. \& Smith, M. Crop evapotranspiration - guidelines for computing crop water requirements - FAO Irrigation and drainage paper 56. (FAO, Rome, 300, D05109, 1998).

11. Chapagain, A. K. \& Hoekstra, A. Y. Water footprints of nations (2004).

12. Chiarelli, D.D., Passera, C., Rosa, L., Davis, K. F., D’Odorico, P. \& Rulli, M. C. The green and blue crop water requirement WATNEEDS model and its global gridded outputs. Scientific Data 
7, $273(2020)$.

13. Chiarelli, D. D., Davis, K. F., Rulli, M. C. \& D’Odorico P. Climate change and large-scale land acquisitions in Africa: Quantifying the future impact on acquired water resources. Advances in Water Resources 94, 231-237 (2016). 
Table S1 | Potential palm oil yields from areas overlapping with 'marginal' rice production where 'marginal' rice production is defined as $<2$ tonnes/ha. Area and yield numbers should be viewed as informed approximations rather than as precise projections.

\begin{tabular}{|c|c|c|c|c|c|c|}
\hline $\begin{array}{l}\text { Climate } \\
\text { Change }\end{array}$ & Irrigation & Inputs & $\begin{array}{c}\text { Oil palm } \\
\text { cultivable } \\
\text { area (M. ha.) }\end{array}$ & $\begin{array}{c}\text { Potential } \\
\text { yield }\left(\mathrm{ha}^{-1}\right)\end{array}$ & $\begin{array}{c}\text { Total } \\
\text { yield } \\
\text { (M. Tn.) }\end{array}$ & $\begin{array}{c}\text { Potential rice } \\
\text { yield loss } \\
\text { (M. Tn.) }\end{array}$ \\
\hline \multirow{6}{*}{$\begin{array}{c}\text { A2 } \\
\text { Scenario }\end{array}$} & \multirow[t]{3}{*}{ Irrigated } & High & 16.08 & 6.78 & 108.92 & 18.94 \\
\hline & & Medium & 16.08 & 4.37 & 70.22 & 18.94 \\
\hline & & Low & 16.08 & 2.09 & 33.53 & 18.94 \\
\hline & \multirow[t]{3}{*}{ Rain-fed } & High & 1.41 & 2.94 & 4.16 & 1.74 \\
\hline & & Medium & 1.52 & 1.88 & 2.86 & 1.84 \\
\hline & & Low & 3.97 & 0.57 & 2.26 & 4.88 \\
\hline \multirow{6}{*}{$\begin{array}{c}\text { No } \\
\text { climate } \\
\text { change }\end{array}$} & \multirow[t]{3}{*}{ Irrigated } & High & 13.48 & 6.60 & 88.96 & 16.35 \\
\hline & & Medium & 13.48 & 4.22 & 56.94 & 16.35 \\
\hline & & Low & 13.48 & 2.01 & 27.11 & 16.35 \\
\hline & \multirow[t]{3}{*}{ Rain-fed } & High & 1.81 & 3.33 & 6.01 & 2.21 \\
\hline & & Medium & 1.96 & 2.12 & 4.16 & 2.21 \\
\hline & & Low & 2.25 & 1.01 & 2.27 & 2.71 \\
\hline
\end{tabular}


Table S2: Total annual water requirement ( $\mathrm{mm} / \mathrm{year})$ for oil palm and rice cultivation in (a) all areas suitable for oil palm cultivation currently used for rice cultivation (Fig. 1a), and (b) areas of overlap between oil palm suitable areas and 'marginal' rice areas (Fig. 1b).

\begin{tabular}{lllll}
\hline Scenario & Crop & Blue water & Green water & Total \\
& & $\begin{array}{l}\text { (from surface and ground water } \\
\text { irrigation) }\end{array}$ & (from rainfall) & \\
& & & & \\
\hline $\begin{array}{l}\text { All areas of } \\
\text { oil palm-rice }\end{array}$ & Oil palm & $1225 \pm 477$ & $633 \pm 352$ & $1858 \pm 288$ \\
\cline { 2 - 5 } \begin{tabular}{l} 
overlap \\
\cline { 2 - 5 }
\end{tabular} & Rice & $333 \pm 324$ & $465 \pm 245$ & $799 \pm 178$ \\
\hline $\begin{array}{l}\text { Oil palm- } \\
\text { marginal }\end{array}$ & Oil palm & $1325 \pm 498$ & $591 \pm 379$ & $1916 \pm 261$ \\
rice overlap & Rice & $388 \pm 347$ & $437 \pm 265$ & $823 \pm 172$
\end{tabular}


Table S3: List of $k_{c}$ values for rice and oil palm disaggregated by month and climate zone.

Note that rice is a monsoonal crop (growing season between May and October in most climate zones), while oil palm is a permanent plantation crop.

Crop Clim Jan Feb $\begin{array}{llllllllll}\text { Mar } & \text { Apr } & \text { May Jun Jul Aug } & \text { Sep } & \text { Oct } & \text { Nov } & \text { Dec }\end{array}$ Zone

\begin{tabular}{|c|c|c|c|c|c|c|c|c|c|c|c|c|c|}
\hline \multirow{6}{*}{ Rice } & 1 & 0 & 0 & 0 & 0 & 1.05 & 1.13 & 1.2 & 1.2 & 0.6 & 0 & 0 & 0 \\
\hline & 2 & 0 & 0 & 0 & 0 & 0 & 1.05 & 1.13 & 1.2 & 1.2 & 0.6 & 0 & 0 \\
\hline & 3 & 0 & 0 & 0 & 0 & 0 & 1.05 & 1.13 & 1.2 & 1.2 & 1.2 & 0.6 & 0 \\
\hline & 4 & 0 & 0 & 0 & 0 & 1.05 & 1.13 & 1.2 & 1.2 & 1.2 & 0.9 & 0 & 0 \\
\hline & 5 & 0 & 0 & 0 & 0 & 1.05 & 1.13 & 1.2 & 1.2 & 0.6 & 0 & 0 & 0 \\
\hline & 6 & 0 & 0 & 0 & 0 & 1.05 & 1.13 & 1.2 & 1.2 & 1.2 & 0.9 & 0 & 0 \\
\hline \multirow{6}{*}{$\begin{array}{l}\text { Oil } \\
\text { Palm }\end{array}$} & 1 & 0.95 & 0.9 & 0.9 & 0.9 & 0.9 & 0.93 & 0.93 & 0.95 & 0.95 & 0.95 & 0.95 & 0.95 \\
\hline & 2 & 0.95 & 0.9 & 0.9 & 0.9 & 0.9 & 0.93 & 0.93 & 0.95 & 0.95 & 0.95 & 0.95 & 0.95 \\
\hline & 3 & 0.95 & 0.9 & 0.9 & 0.9 & 0.9 & 0.93 & 0.93 & 0.95 & 0.95 & 0.95 & 0.95 & 0.95 \\
\hline & 4 & 0.95 & 0.9 & 0.9 & 0.9 & 0.9 & 0.93 & 0.93 & 0.95 & 0.95 & 0.95 & 0.95 & 0.95 \\
\hline & 5 & 0.95 & 0.9 & 0.9 & 0.9 & 0.9 & 0.93 & 0.93 & 0.95 & 0.95 & 0.95 & 0.95 & 0.95 \\
\hline & 6 & 0.95 & 0.9 & 0.9 & 0.9 & 0.9 & 0.93 & 0.93 & 0.95 & 0.95 & 0.95 & 0.95 & 0.95 \\
\hline
\end{tabular}




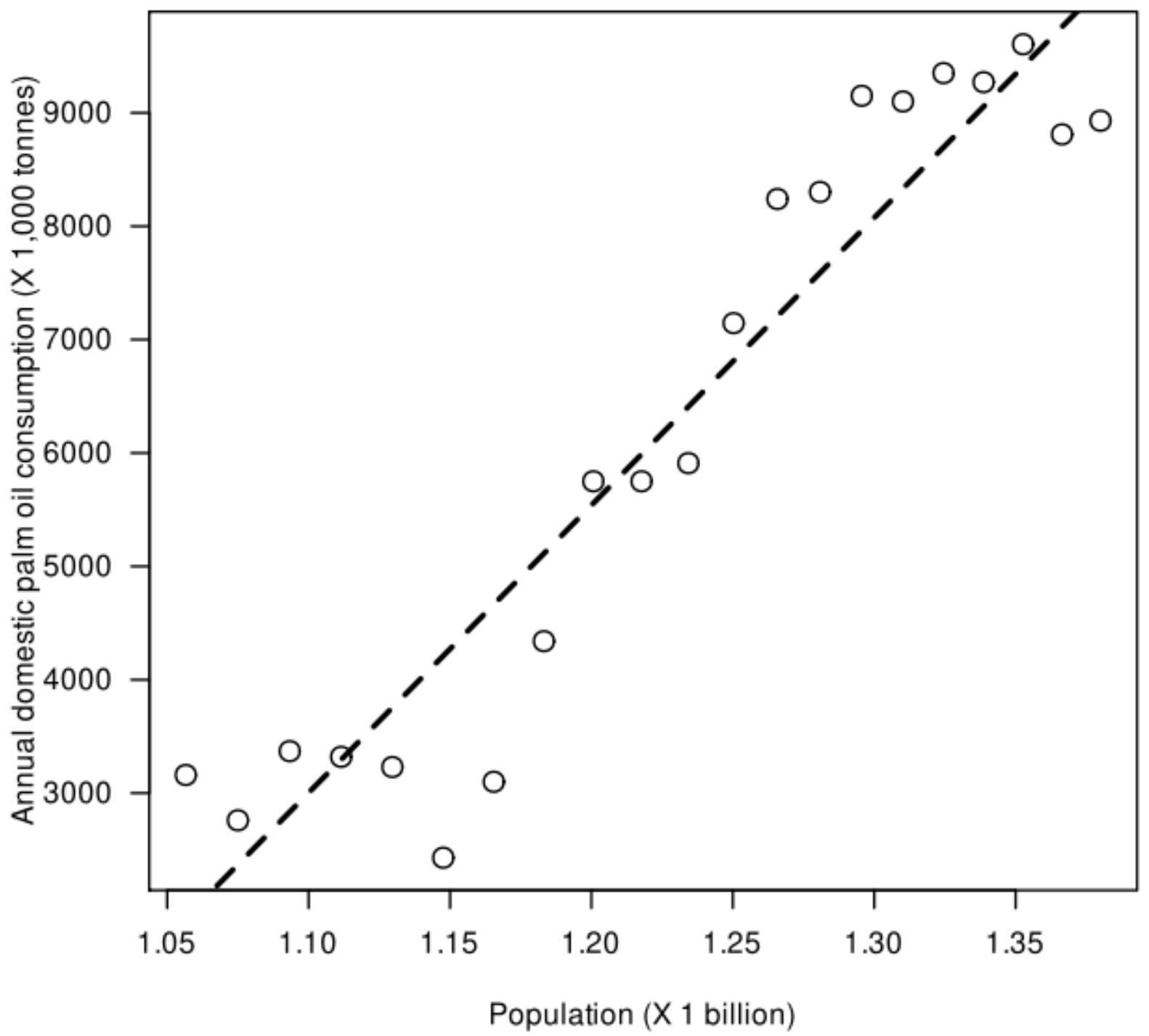

Figure S1 | In India, annual palm oil consumption is strongly positively related to population size (2000-01 to 2019-20). Data are sourced from the Foreign Agricultural Service of the United Stated Department of Agriculture). The recent decrease in India's palm oil consumption (top right corner) is because of the ban on imports from Malaysia, higlighting the need for India to enhance self-sufficiency in palm oil production. 


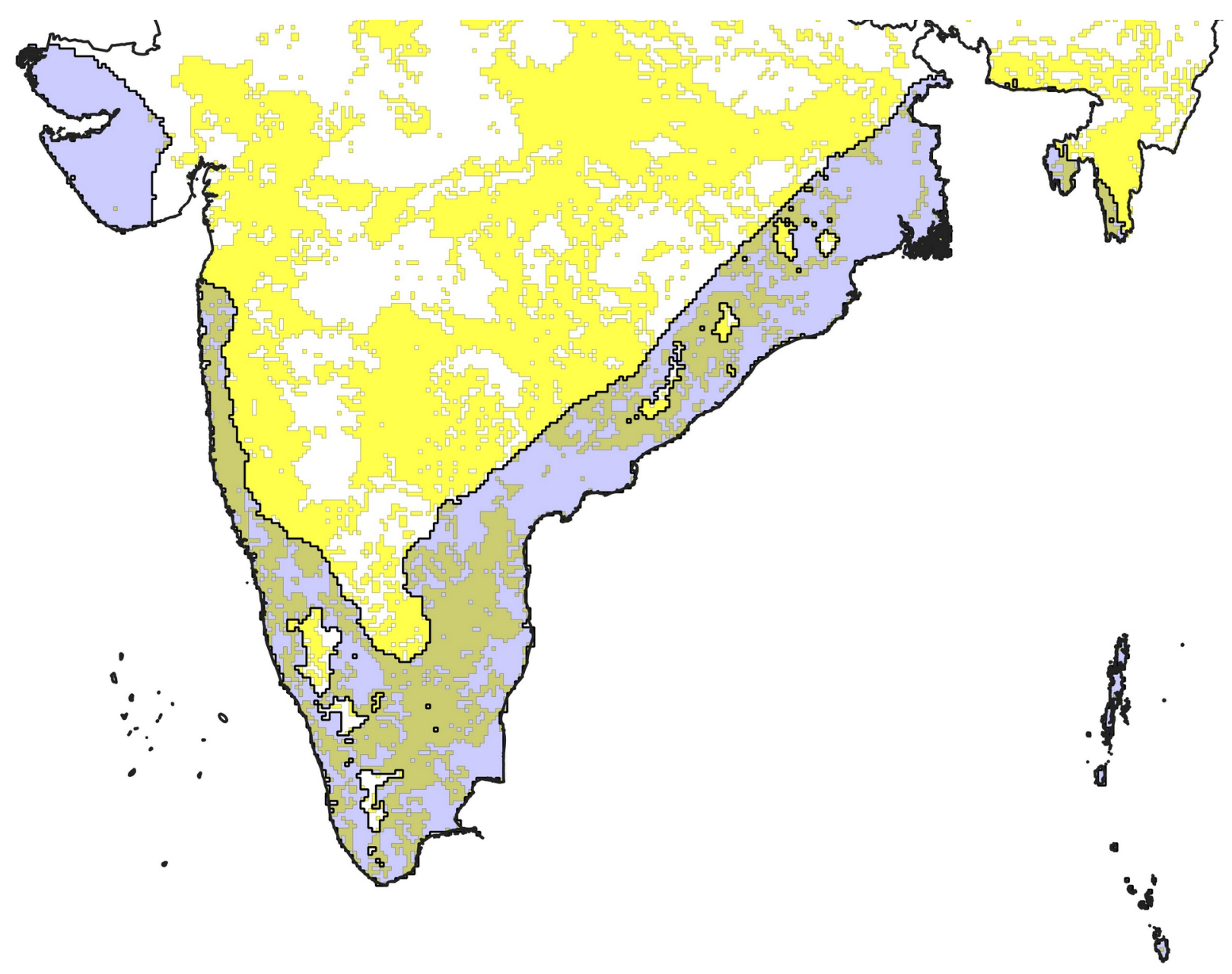

Figure S2 | Overlaps (green) between marginal rice producing regions (yellow) and areas suitable for the cultivation of oil palm under the A2 climate scenario with artifical irrigation and high agricultural inputs (blue outlined in black). 


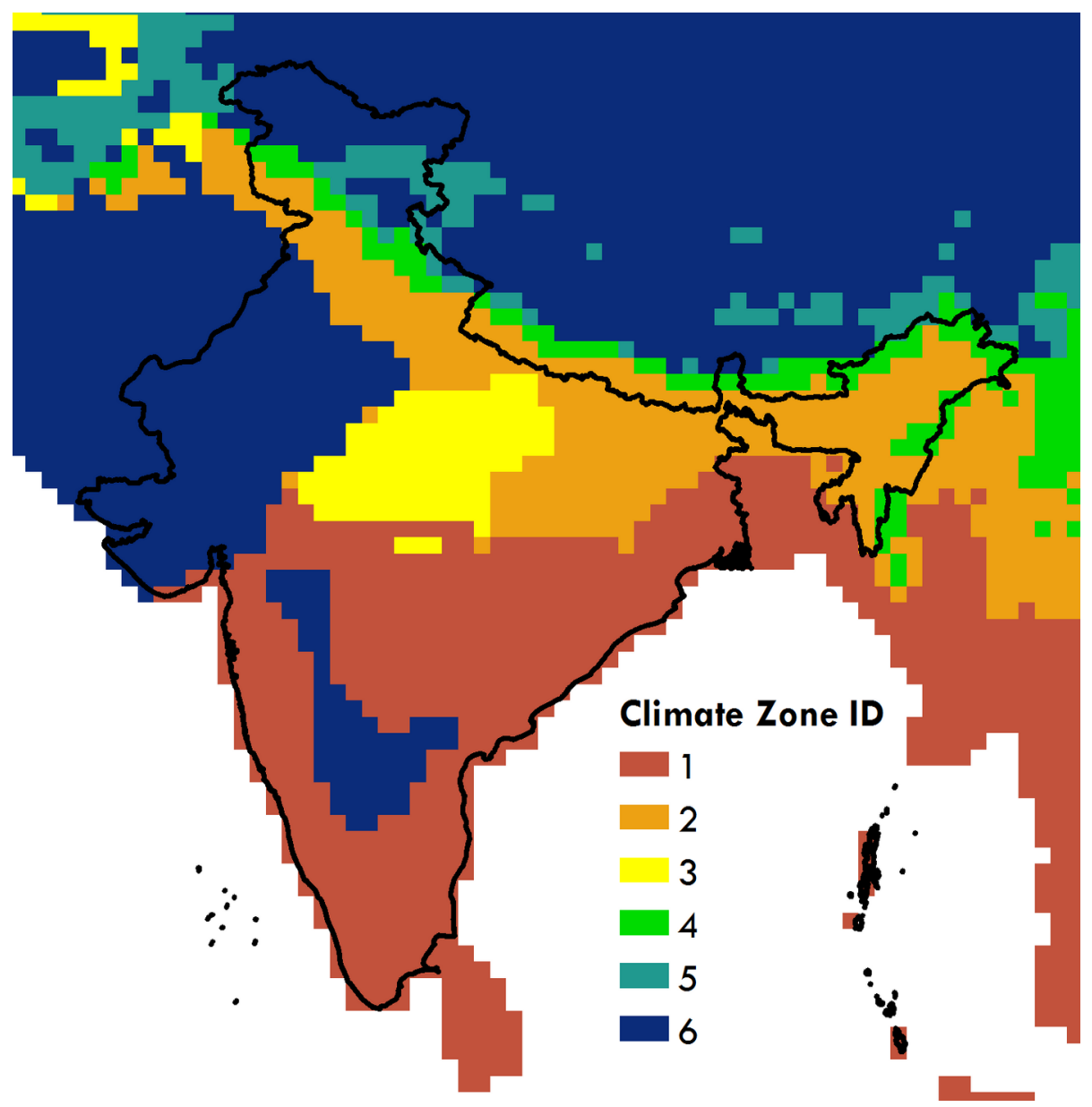

Figure S3 | Map of climate zones based on Kottek et al. 2006. (World map of the KöppenGeiger climate classification updated. Meteorologische Zeitschrift 15: 259-263). Areas suitable for oil palm cultivation in India lie largely in Climate Zone 1 (see Fig. 1). 